\title{
Effect of Particulate Reinforcement on the Mechanical Properties of Al2024-WC MMCs
}

\author{
K. Punith Gowda1, J. N. Prakash1,2, Shivashankare Gowda ${ }^{3}$, B. Satish Babu' ${ }^{1}$ \\ ${ }^{1}$ Department of Mechanical Engineering, East West Institute of Technology, Bengaluru, India \\ ${ }^{2}$ St Johns College of Engineering and Technology, Yemmiganur, India \\ ${ }^{3}$ Swarnandhra Institute of Engineering \& Technology, Narasapur, India \\ Email:pgpunith@gmail.com
}

Received 24 September 2015; accepted 9 November 2015; published 12 November 2015

Copyright (C) 2015 by authors and Scientific Research Publishing Inc.

This work is licensed under the Creative Commons Attribution International License (CC BY). http://creativecommons.org/licenses/by/4.0/

\begin{abstract}
The present work reveals the study of mechanical properties of Al2024-Tungsten carbide MMCs containing tungsten carbide (WC) particulates. The reinforcing particulates in the Al2024 alloy were varied from $0 \%$ to $5 \%$ by weight. The vortex method of cast production was employed to fabricate the MMCs, in which the reinforcement was poured into the vortex created by stirring the molten metal by means of a mechanical agitator. The composite so produced was subjected to a series of mechanical tests. The results of this study revealed that as the tungsten carbide particle content was increased, there were significant increases in the ultimate tensile strength, hardness and young's modulus, compressive strength, accompanied by a reduction in its ductility. An attempt is made in the paper to provide explanations for these phenomena.
\end{abstract}

\section{Keywords}

Aluminium 2024 Alloys, Tungsten Carbide, Stir Casting, Mechanical Properties

\section{Introduction}

Metal matrix composites (MMCs) are becoming more and more attractive materials for industrial and aerospace applications since their properties can be tailored through the addition of selected reinforcements [1] [2]. MMCs have their own essence for the specific applications because of their specific strength and modulus at elevated and room temperatures [3]. It is understood that the elastic properties of MMCs are strongly influenced by micro structural parameters of the reinforcement such as shape, size, orientation, distribution and 
volume fraction [4].

AMCs have proved themselves to be a best choice as engineering materials in recent decades. The introduction of a ceramic reinforcement into a metal matrix produces a composite material that yields an attractive combination of physical and mechanical properties which cannot be obtained with monolithic alloys.

Owing to the wider commercial applications, there is an ever increasing demand to know about the processing techniques and mechanical behaviour of particulate MMCs. The ease of availability and low cost manufacturing process adopted has gained the attention of researchers to work in the area of particulate composites.

Aluminium alloy-based particulate-reinforced composites have a large potential for a number of engineering applications. Aiming of reinforcing $\mathrm{Al}$ alloy based matrices with ceramic particles is mainly due to the low weight to volume ratio, low coefficient of thermal expansion and high strength and modulus of the reinforcements and also due to their availability. Among the various useful aluminium alloys, aluminium alloy 2024 is typically characterized by properties such as fluidity, cast ability, corrosion resistance and high strength-weight ratio. This alloy has been commonly used as a base metal for MMCs reinforced with a variety of fibres, particles and whiskers [5]-[7].

Past studies revealed that if the particle size of reinforcement was in the range (50 $\mu \mathrm{m}$ to $200 \mu \mathrm{m})$, the composite provided optimum results with respect to mechanical properties and tribological properties [8]. The most common reinforcements are alumina, $\mathrm{SiC}, \mathrm{B}_{4} \mathrm{C}$, TiC, graphite and $\mathrm{WC}$ to explore better mechanical properties.

Awerbuch et al. [9] has worked on aluminium 6061 and showed that the compressive deformation can be enhanced more than 50 percent with a specimen length to diameter ratio equal to unity, which in turn improves compressive strength. Hence, in the present study of investigation, priority is also given to the compressive properties along with tensile properties like ductility, young's modulus, UTS and hardness. Aluminium 2024 is widely used in aircraft structures, rivet hardware, truck wheels, screw machine products, and other miscellaneous structural applications [10].

In the present investigation, aluminium alloy 2024 was used as the matrix material. Al2024 alloy [11] has the higher specific strength and ductility of the aluminium alloys with excellent machinability and good bearing and wear properties, similar to Al6061 alloy [12]. Most of the particulate reinforced metal matrix composites are produced by liquid metallurgy, sometimes known as the "vortex method" [13], although many different processes for fabricating these cast composites are also available which have been reported by various researchers.

In the present work, the "vortex method" of producing AMC's, in which Tungsten carbide has been used as the candidate reinforcements of particulate sizes ranging from 60 to $90 \mu \mathrm{m}$ and added to the vortex formed in the Al2024 melt above its liquidus temperature. Since the hardness, ultimate tensile strength (UTS), compressive strength, young's modulus and ductility of the composite material are all vital properties of a structural material, the present investigation aims at studying these properties in the Al2024 alloy-particulate composites.

\section{Experimental Details}

The properties of materials adopted and methods followed for the fabrication and testing of MMCs in the present studies are presented in the following sections.

\subsection{Matrix and Reinforcement Materials Details}

The matrix for the present studies selected was Al2024 alloy and were procured from Fenfee Metallurgical, Bangalore, in the form of ingots. The chemical composition of Al2024 alloy was supplied commercially with the chemical composition (in weight percent) of $4.850 \% \mathrm{Cu}, 1.310 \% \mathrm{Mg}, 0.667 \% \mathrm{Mn}, 0.254 \% \mathrm{Fe}, 0.110 \% \mathrm{Si}$, $0.079 \% \mathrm{Zn}, 0.033 \% \mathrm{Cr}, 0.008 \% \mathrm{Ti}$ and balance Al. The reinforcing materials selected were tungsten carbide (WC) of $60 \mu \mathrm{m}$ particle size and the properties of the matrix and reinforcement materials used are presented in the Table 1.

\subsection{Preparation of Composites}

The Al2024-WC composites were prepared by the vortex method [8]. The tungsten carbide contents used for the preparation of the composites were $0 \%, 1 \%, 2 \%, 3 \%, 4 \%$ and $5 \%$. Addition of Tungsten Carbide into the molten aluminium alloy melt above its liquidus temperature of $500^{\circ} \mathrm{C}$ was carried out by creating a vortex in the melt using a mechanical stainless steel stirrer coated with aluminite to prevent migration of ferrous ions from the stirrer material into the aluminium alloy melt. The melt was rotated at a speed of $500 \mathrm{rpm}$ over a period of eight 
Table 1. Properties of matrix and reinforcement materials.

\begin{tabular}{ccccc}
\hline Material & Elastic Modulus (GPa) & Density (g/cc) & Hardness (BHN) & Tensile Strength (MPa) \\
\hline Al2024 & 76 & 2.78 & 82 & 112.62 \\
WC & 627 & 14.9 & $1630^{*}$ & 5000 \\
\hline${ }^{*} \mathrm{Kg} / \mathrm{mm}^{2}$. & & & &
\end{tabular}

minutes in order to create the necessary vortex. The WC particles were preheated to $400^{\circ} \mathrm{C}$ and added to the melt through the vortex. The melt was subsequently degassed by passing hexa-chloro-ethane $\left(\mathrm{C}_{2} \mathrm{Cl}_{6}\right)$ tablets. The molten metal was then poured into permanent moulds for casting. The cast specimen of size $25 \times 300 \mathrm{~mm}^{2}$ MMCs were obtained.

\subsection{Testing of Specimens}

Carefully polished and mirror finished specimens were examined under Scanning Electron Microscope (SEM) to obtain microphotographs. Tensile tests were conducted at room temperature using a Universal Testing Machine (UTM) in accordance with ASTM Standard E 8-82. The tensile specimens of diameter $12.5 \mathrm{~mm}$ and gauge length $62.5 \mathrm{~mm}$ were machined from the cast composites with the gauge length of the specimens parallel to the longitudinal axis of the castings. For each composite, four tensile test specimens were tested and the average values of the UTS, Young's modulus and ductility were measured.

The hardness tests were conducted in accordance with ASTM Standard E 10 using a Brinell hardness tester with a ball indenter of $5 \mathrm{~mm}$ diameter and a load of $250 \mathrm{~kg}$. The load was applied for 30 sec. eight hardness readings were taken for each specimen at different locations to circumvent the possible effects of particle segregation. Compression tests were conducted on a UTM in accordance with ASTM Standard E 9 at room temperature. In this test the compression loads were gradually increased and the corresponding strain was measured until the specimen failed. Each result is an average of four readings.

\section{Results and Discussions}

\subsection{Microstructure Studies}

Micrographs of Al2024 alloy and Al2024-WC composites are observed from Figure 1(a) \& Figure 1(b). The soundness of prepared casted composites in terms of increased density, reduced porosity with uniform distribution of WC particulates in the matrix alloy was noticed with the help of SEM analysis [14]. SEM structures also revealed good bonding among matrix and reinforcement particles which yields better load transfer from matrix to reinforcement material Figures $1(\mathrm{c})-(\mathrm{f})$.

\subsection{Hardness}

The effect of WC reinforcement on the hardness of casted Al2024-WC particulate composites is observed from Figure 2. Hardness test helps in understanding material resistance to surface penetration and maximum stress required to cause specific surface deformation. The hardness value of each test specimen is an average of six test measurements. It is observed from the test results that increase in the tungsten carbide content made increase in hardness value monotonously. In fact, as the WC content is increased from $0 \%$ to $3 \%$ the hardness increases by about $9 \%$.

In metals, there is a relation between Ultimate Tensile Strength (UTS) and hardness, increase in UTS yields increase in hardness; same would be seen in processed composites [15]. The reason for improved hardness is due to hard WC dispersoid contributing positively to the hardness of composites. The hardness value increased to about $9 \%$ for $3 \mathrm{wt} \%$ of WC reinforcement, compared to as cast Al2024 alloy without reinforcement. There after a decrease in hardness was observed for $4 \mathrm{wt} \%$ of WC reinforcement, probably due to the voids which nucleate during the plastic straining of the reinforcement.

\subsection{Ultimate Tensile Strength}

Figure 3 shows the graph of effect of reinforcement content on ultimate tensile strength (UTS) of processed 


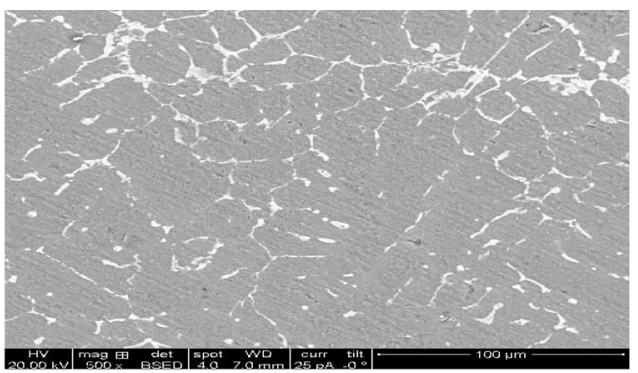

(a) Al 2024 alloy

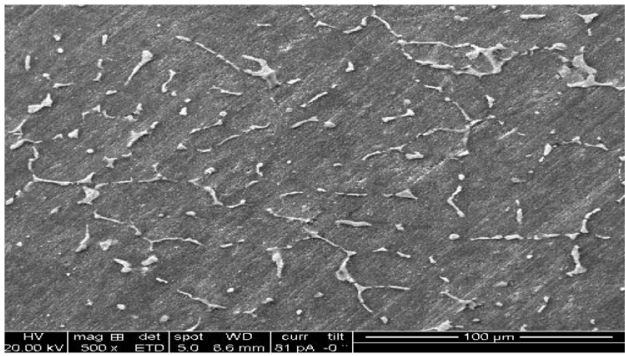

(c) Al 2024 alloy-2\% WC

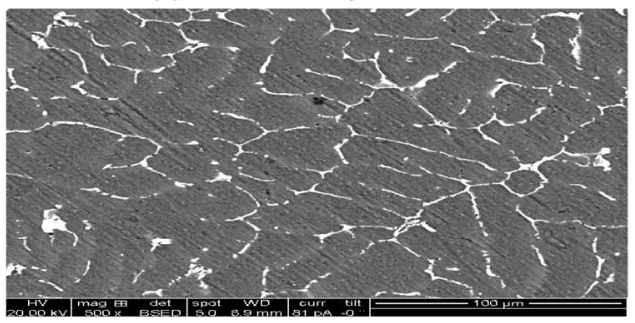

(e) Al 2024 alloy-4\% WC

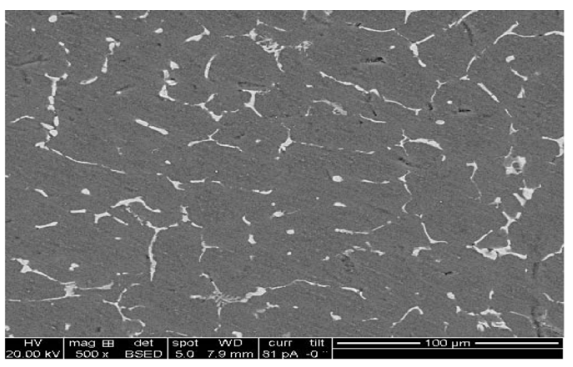

(b) Al 2024 alloy-1\% WC

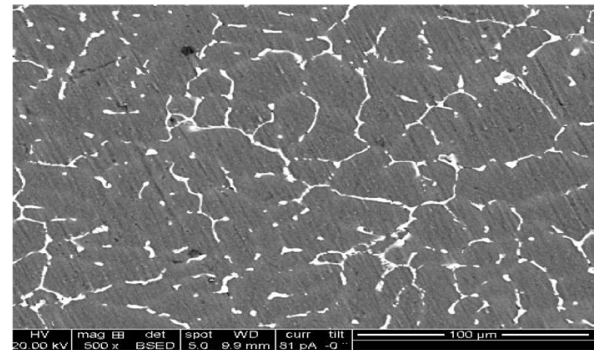

(d) Al 2024 alloy-3\% WC

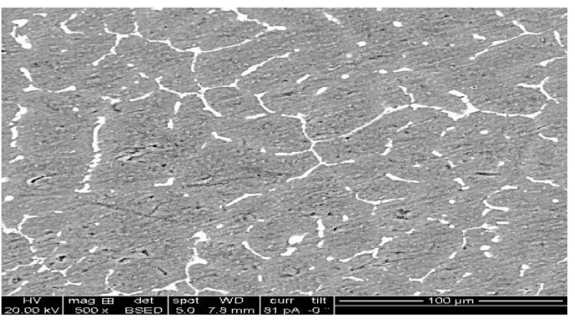

(f) Al 2024 alloy-5\% WC

Figure 1. SEM structures of Al2024 and Al2024-WC MMCs at 500× magnification for $50 \mu \mathrm{m}$.

\section{As Cast-Hardness(BHN)}

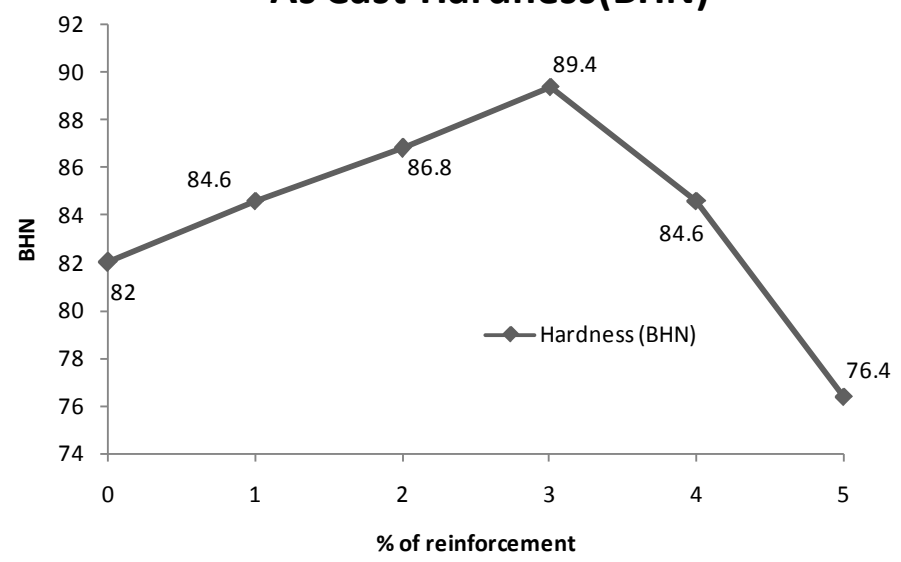

Figure 2. Effect of the WC content on hardness.

composites. Each value of UTS is an average of six measurements. From the graphs is noticed that improvement of tensile strength was achieved up to $3 \mathrm{wt} \% \mathrm{WC}$, however it decreased beyond $4 \mathrm{wt} \%$ WC. Better tensile strength was found at $3 \mathrm{wt} \% \mathrm{WC}$. As the WC content is increased from $0 \%$ to $3 \%$, the UTS increased by about $57.5 \%$. The decrease in tensile strength of the composites beyond $3 \mathrm{wt} \% \mathrm{WC}$ is attributed to improper bonding between the matrix and reinforcement materials. Finer the grain size better is the hardness and strength of composites. The increase in UTS can be attributed to the presence of hard WC particulates that impart strength to the 


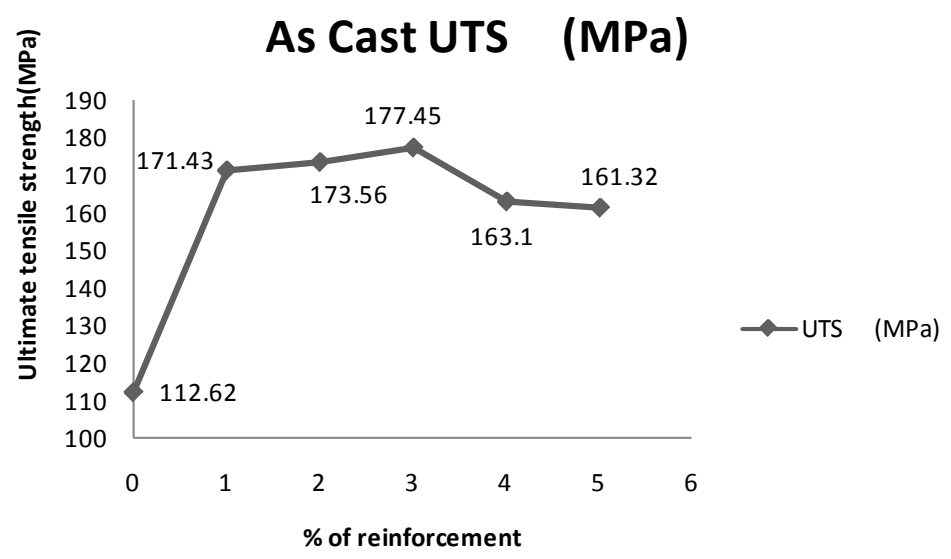

Figure 3. Effect of the WC on ultimate tensile strength.

matrix alloy, thereby providing enhanced resistance to tensile stresses.

Addition of WC particulates results in decreasing the interspatial distance between Al 2024 and also helps in pile up of dislocations. This in turn causes restriction in plastic flow due to uniform distribution of particulates in Al 2024 alloy thereby improving tensile strength of the processed composite. Similar observations were made by Ghosh and Ray [16], who fabricated $\mathrm{Al}_{2} \mathrm{O}_{3}$ particulate reinforced aluminium alloy composites using the compo-casting method and by $\mathrm{McCoy}$ et al. [17] who produced $\mathrm{TiB}_{2}$-particulate-reinforced aluminium alloy composites with particulate contents ranging from 10 to $25 \mathrm{vol} \%$.

\subsection{Youngs Modulus}

From Figure 4, the percentage variation in Young's modulus provides a comparative insight in to the actual experimental results recorded for the Al2024-WC particulate reinforced composites. It is observed from the result that addition of WC content in to the Al2024 matrix improved young's modulus of prepared composite monotonously by significant amount. In fact, as the WC content is increased from $0 \%$ to $3 \%$, the Young's modulus increases by about $47.6 \%$ and when increased from $3 \%$ to $4 \%$ the Young's modulus decreases monotonically. The increase in young's modulus is closely attributed to the prediction of rule of mixture. McDanels [18] had reported similar results for particle reinforced Aluminium composites.

\subsection{Ductility}

Figure 5 shows the effect of the reinforcement content on the ductility of cast Al2024-WC particulate composites measured in terms of percentage elongation. The ductility of the composite material is less compared to as cast Al 2024 alloy. The brittleness also increased with increasing reinforcement content, since the matrix material suffered with ductility due to reinforcement. As the WC content increased from $0 \%$ to $5 \%$, the ductility dropped by about $100 \%$. similar results were reported by Beitz W. and Kuttner K. H. [19] \& Zhu H. X. and Liu S. K [20]. The reduction in ductility is due to the hard ceramic phase due to localized crack initiation and em-brittlement owing to local stress concentration sites at the particle reinforcement interface. The reinforcing particles resist the passage of dislocations by creating stress fields. Past studies have also revealed, loss of ductility due to the voids nucleating during plastic straining of the reinforcement.

\subsection{Compressive Strength}

It is observed from Figure 6, that the compressive strength of the composites is higher than that of the base alloy due to the presence of hard WC particles. The WC particles have higher compressive strength than the matrix. Hence an increase in compressive strength is observed with increasing wt\% of reinforcement. The compressive strength however decreased with $4 \mathrm{wt} \%$ of WC. Webster [21] and Towle et al. [22] also reported about the increase in compressive strength while working on whisker reinforced composites. The increase in compressive strength can also be attributed to decrease in inter particle spacing between WC particles, since WC is much harder than the matrix. The hard ceramic WC particles resist deformation stress whilst increasing composite 


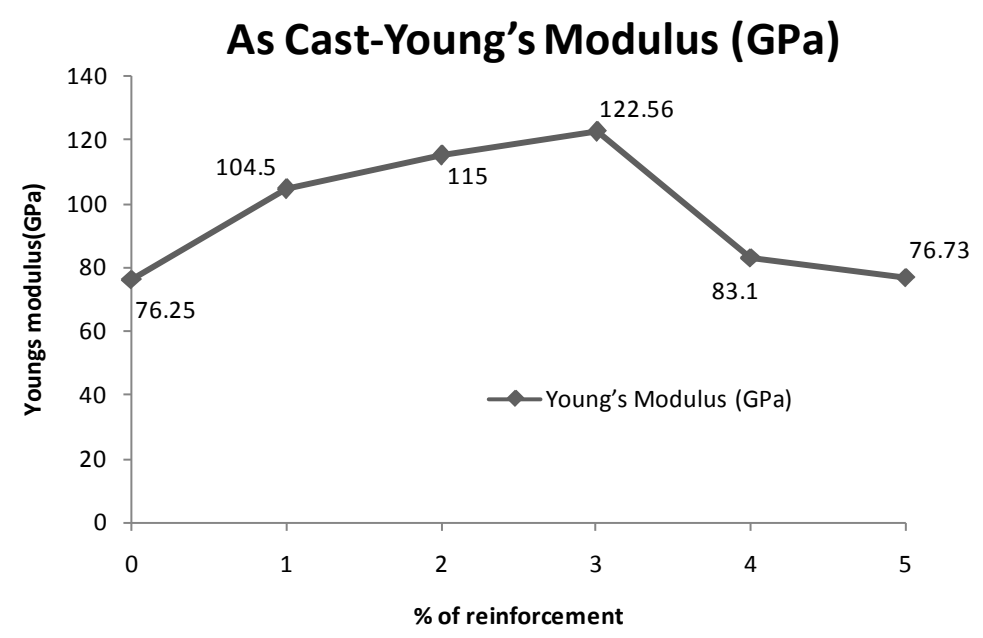

Figure 4. Effect of the WC content on young's modulus.

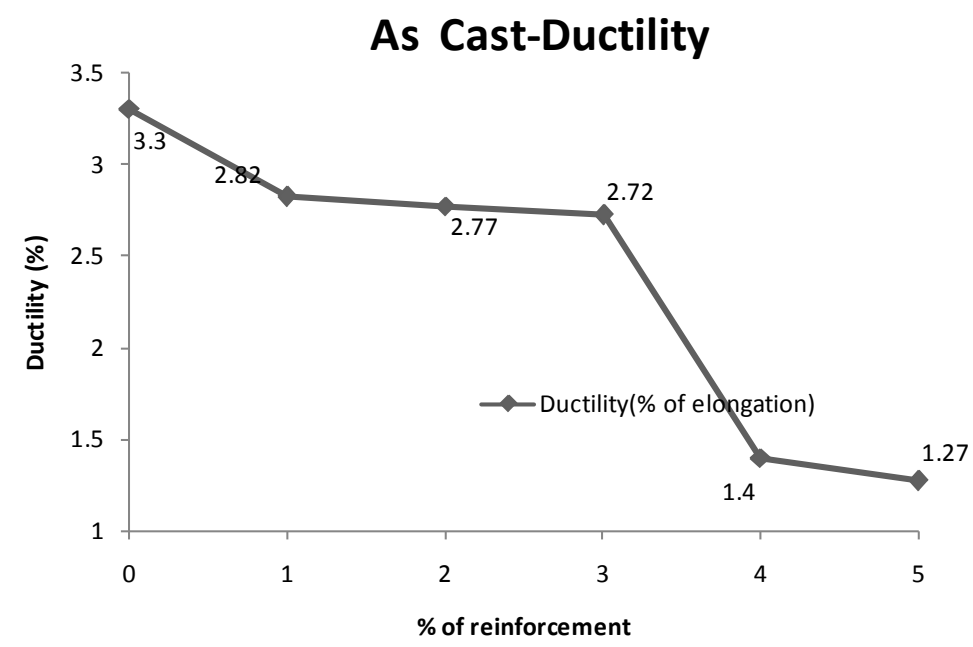

Figure 5. Effect of the WC content on ductility.

\section{Ultimate Compressive Strength(MPa)}

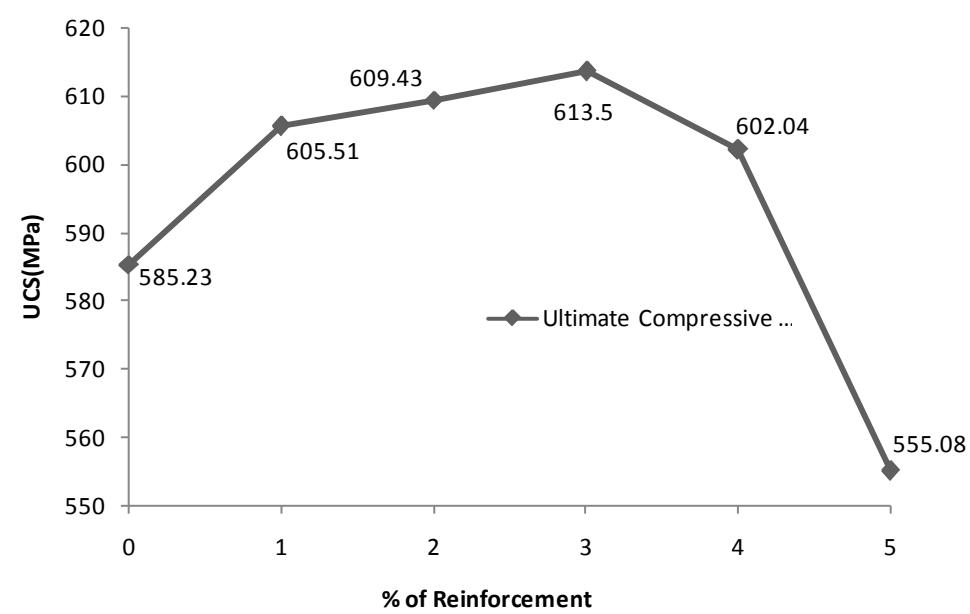

Figure 6. Effect of the WC content on ultimate compressive strength. 
strength of the composite. Nevertheless, the addition of hard ceramic particulates has caused the MMCs to behave as brittle rather than ductile materials, as is evident from the above results.

\section{Conclusions}

The significant conclusions of the studies on Al2024-WC metal matrix composites are as follows.

1) Al2024-WC composite was prepared successfully using liquid metallurgy techniques by incorporating the reinforcing particulates.

2) It was found that increasing the carbide content within the aluminium matrix results in significant increase in the ductility, UTS, compressive strength and young's modulus, however hardness values decreased with increasing reinforcing content.

3) The properties of the as cast Al2024-WC composites significantly improved by varying the amount of WC. It was found that increasing the WC content within the matrix material, resulted in significant improvement in mechanical properties like hardness, tensile strength, and compressive strength at the cost of reduced ductility.

4) Highest values of mechanical properties like hardness, tensile strength and compressive strength were found at $3 \mathrm{wt} \% \mathrm{WC}$.

\section{References}

[1] Everett, R.K and Arsenault, R.J. (1991) Metal Matrix Composites: Mechanisms and Properties. Academic Press, San Diego.

[2] Kocjak, M.J., Kahtri, S.C., Allison, J.E. and Jones, J.W. (1993) Fundamentals of Metal Matrix Composites. In: Suresh, S., Mortensen, A. and Needleman, A., Eds., Butterworth-Heinemann, Boston.

[3] Lloyd, D.J. and Brotzen, F.R. (1994) Particle Reinforced Aluminium and Mg Matrix Composites. International Materials Reviews, 39, 1-39. http://dx.doi.org/10.1179/imr.1994.39.1.1

[4] Lei, M. and Ledbetter, H. (1994) Communications: Elastic Constants of SiCp/Al: Measurements and Modeling. Metallurgical and Materials Transactions, 25A, 2832-2835. http://dx.doi.org/10.1007/BF02649234

[5] Vogelsang, M., Arsenault, R.J. and Fisher, R.M. (1986) In-Situ HVEM Study of Dislocation Generation at Al/SiC Interfaces. Metallurgical Transactions A, 17, 379-389. http://dx.doi.org/10.1007/BF02643944

[6] Pai, B.C., Ray, S., Prabhakar, K.V. and Rohatgi, P.K. (1976) Fabrication of Aluminium Alumina (Magnesia) Particulate Composites in Foundries Using Magnesium Additions to the Melts. Materials Science and Engineering, 24, 31. http://dx.doi.org/10.1016/0025-5416(76)90092-6

[7] Sato, A. and Mehrabian, R. (1976) Aluminium Matrix Composites: Fabrication and Properties. Metallurgical Transactions B, 7, 443-451. http://dx.doi.org/10.1007/BF02652716

[8] Pai, B.C., Pillai, R.M. and Sathyanarayana, K.G. (1994) Prospects for Graphite Aluminium Composites in Engineering Industries. Indian Journal of Engineering and Materials Science, 1, 279.

[9] Awerbuch, J., Goering, J. and Busking, K. (1988) In Mini Mechanics Analysis and Testing of Short Fibre Composites: Experimental Methods and Results. American Society for Testing and Materials, Philadelphia, Vol. 121, 964.

[10] Cubberly, W.H. (1979) Properties and Selection: Non-Ferrous Alloys and Pure Metals. Metals Handbook, 9th Edition, ASM, Metals Park.

[11] Murthy, I.N., Babu, N.A. and Rao, J.B. (2014) Comparative Studies on Microstructure and Mechanical Properties of Granulated Blast Furnace Slag and Fly Ash Reinforced AA 2024 Composites. Journal of Minerals \& Materials Characterization \& Engineering, 2, 319-333. http://dx.doi.org/10.4236/jmmce.2014.24037

[12] Smith, W.F. (1993) Structure and Properties of Engineering Alloys. 2nd Edition, McGraw-Hill, New York, 566.

[13] Kok M. (2005) Production and Mechanical Properties of $\mathrm{Al}_{2} \mathrm{O}_{3}$ Particle-Reinforced 2024 Aluminium Alloy Composites. Journal of Materials Processing Technology, 161, 381-387.

[14] Ramesh, C.S., Keshavamurthy, R., Channabasappa, B.H. and Ahmed, A. (2008) Microstructure and Mechanical Properties of Ni-P Coated $\mathrm{Si}_{3} \mathrm{~N}_{4}$ Reinforced Al6061 Composites. Materials Science and Engineering: A, 502, 99-106. http://dx.doi.org/10.1016/j.msea.2008.10.012

[15] Ramesh, A., Prakash, J.N., Gowda, A.S.S.S. and Appaiah, S. (2009) Comparison of the Mechanical Properties of AL6061/Albite and AL6061/Graphite Metal Matrix Composites. Journal of Minerals \& Materials Characterization \& Engineering, 8, 93-106. http://dx.doi.org/10.4236/jmmce.2009.82009

[16] Ghosh, P.K. and Ray, S. (1986) Effect of Porosity and Alumina Content on the Mechanical Properties of Compocast Aluminium Alloy-Alumina Particulate Composite. Journal of Materials Science, 21, 1667-1674. 
[17] McCoy, J.M. and Warner, F.E. (1988) Dendritic Solidification in Particle Reinforced Cast Aluminium Composites in Cast Reinforced Metal Composites. In: Fishman, S.G. and Dhingra, A.K., Eds., ASM, 237-242.

[18] McDanels, D.L. (1985) Analysis of Stress-Strain, Fracture and Ductility Behaviour of Aluminium Matrix Composites Containing Discontinuous SiC Reinforcement. Metallurgical Transactions A, 16, 1105-1115. http://dx.doi.org/10.1007/BF02811679

[19] Beitz, W. and Kuttner, K.H. (Eds.) (1994) Dubbel Handbook of Mechanical Engineering. Springer-Verlag, London, D8. http://dx.doi.org/10.1007/978-1-4471-3566-1

[20] Zhu, H.X. and Liu, S.K. (1993) Mechanical Properties of Squeeze Cast Zinc Alloy Matrix Composites Containing Alpha-Alumina Fibers. Composites, 24, 437-442. http://dx.doi.org/10.1016/0010-4361(93)90251-3

[21] Webster, D. (1982) Effect of Lithium on the Mechanical Properties and Microstructure of SiC Whisker Reinforced Aluminium Alloys. Metallurgical Transactions A, 13A, 1511-1519.

[22] Towle, D.J. and Fried, C.M. (1993) Comparison and Compressive and Tensile Properties of Mg Based MMCs. Materials Science and Technology, 9, 35-41. http://dx.doi.org/10.1179/mst.1993.9.1.35 